(2016) 'Olfactory control, aroma power and organizational smellscapes', in Henshaw, V. Warnaby, G. McClean, K. \& Perkins, C. (eds.) Designing with Smell: Practices, Techniques and Challenges, Routledge: London, in print

\title{
Olfactory control, aroma power and organizational smellscapes
}

\section{Samantha Warren (Cardiff University, UK) \\ Kathleen Riach (Monash University, Australia)}

\begin{abstract}
This chapter explores 'aroma management' in consumption spaces, workplaces and other institutional settings, reviewing debates in architectural design, sensory marketing and the natural sciences. We argue the biologically deterministic assumptions upon which these developments are premised silences considerations of power and ethics and propose an alternative socio-cultural reading of these phenomena, taking our lead from sensory anthropology. We highlight the role culture plays in the creation of organizational olfactory experiences and demonstrate that olfactory design and aroma management cannot be taken as independent of either professional norms or the employee bodies that experience, negotiate and themselves contribute to organizational smellscapes.
\end{abstract}

\section{Introduction}

In this chapter we reflect on the practice of aroma management in spaces where people interact such as workplaces and other institutional settings, considering how issues of control and power may arise - inadvertently or deliberately - within smell practices. The 'smellscape' is an increasingly important part of organizations' physical and cultural design, 
underpinned by debates in architectural design (Pallasmaa, 2005), marketing and sensory branding (Brumfield, \& Gouldney, 2008) and the natural sciences (Barker, Grayhem, Koon, Perkins, Whalen, \& Raudenbush, 2003). Through reflecting on a range of recent smell practices predominantly apparent in retail spaces and service sector environments, we argue that the biologically deterministic assumptions upon which these developments are premised - namely that smell subliminally and predictably 'short circuits' the brain to influence behavior - silences considerations of power and ethics surrounding hierarchy, control and individual sovereignty. We highlight the role these issues play in the interpretation of organizational olfactory experiences. Our intention is therefore to sensitize designers to the lived experience of smell through an alternative reading of a socio-cultural phenomenon. As such, smell cannot be taken as independent of either professional or occupational norms or the employee bodies that experience, negotiate and themselves contribute to organizational smellscapes.

\section{The power of aroma in organizational environments}

The commercialization of smell (e.g., the realization of added value using olfactory means) has a long history and continues to be big business at the level of the body through deodorants and perfumes. However, increasingly smell is promoted more broadly as a means of evoking atmospheres conducive to productivity and used to augment all kinds of products and market exchanges (Classen, Howes, \& Synnott, 1994). The fields of 'sensory marketing' and 'sensory branding' are gathering momentum, developed from a more general interest in 'experiential marketing' of the late 1990s (Schmitt, \& Simonson 1997; Schmitt, 2000; Pine, \& Gilmore 1997; La Salle, \& Britton 2003). Subsequently, popular marketing texts, including Martin Lindstrom's ‘Brand Sense’ (Lindstrom, 2010), Renvoise and Morin’s (2007) introduction to neuro-marketing, Brumfield and Gouldney's (2008) treatise on what 
they refer to as the 'scent revolution', and Derval's (2010) 'The Right Sensory Mix' all offer advice about, and accounts of, smell and the consumer. Examples of these practices within the retail and service sector in particular are numerous, and include Harrods who have trialed a variety of aromas in different areas of their store (Aromaco, n.d.) and the formal clothing chain 'Pink' who add the smell of freshly laundered cotton to their atmosphere (Lindstrom 2010, p. 104). Lindstrom (2010) cites the automotive industry, shopping malls and retail outlets as examples where scents have been introduced to manipulate consumer responses. Bespoke scents are also becoming an increasingly prominent element of the 'branding mix' with scent engineering companies such as The Aroma Company Europe Ltd. (www.aromaco.co.uk), and Brandaroma (www.brandaroma.com) providing organizations the opportunity to create bespoke sensory environments for consumers and other stakeholders. Samsung and Sony have similarly commissioned smells as signature scents for their stores (Tischler, 2005) and it appears that the branding of smells is not limited to physical spaces either; French company Exhalia create and sell software and hardware smell solutions for marketing multimedia. According to their website, these are not just for companies where one would expect smell to be part of the product. For example, the municipal website of the city of Grasse, in France, and 'Stations Nouvelle Vague de Bretagne' (a portal for rail travel in the French Brittany region) both have 'scented internet sites' (Exhalia n.d.). Even the Catalan Socialist Party have introduced a branded scent (Hamilos, 2004). These texts have been accompanied by academic commentary too such as Hultén, Broweus and van Dijk,'s (2009) textbook on 'Sensory Marketing' and Krishna's (2011) edited collection.

These writers believe that smell has a role to play in the design of consumer lives in ways that are just as important as the design organization and physical arrangement of space, lighting, and acoustics. This in itself is not a new idea: as Corbett (2006, p. 335) notes, the 
management of smells via airflows around a building was a pressing concern for architects as far back as the Enlightenment, where deodorisation was key and "the degree of stench [in a building] became the measure of the architect's efficiency". More recently, this has involved conquering odor by attempting to achieve a blank canvas of 'no' odor, through air conditioning, for example. However, Panos (2001, cited in Malnar \& Vodvarka 2004, p. 281) suggests that the smell of a building is now one of six dimensions which good sensory design should use to enrich users' journey through space beyond the physical mechanics of navigation. "[T]he act of building inevitably involves a metaphysical message - a 'metaphysical experience' " (Pallamasaa 1980, p. 41), and may include a consideration of 'nostalgia' in the smell around the approach to a building or the enhancement/ elimination of smells and differences between the smells of different rooms (Panos 2001).

As suggested above, the coordination and control of smells that appear as a byproduct or 'naturally' appear in a space is only one component of smell management in terms of design. Smell Management entails the deliberate introduction, choreography and manipulation of smell as a resource which will achieve ends beyond the smell itself. For example, Diaconu's (2007) tripartite framework for olfactory design in public space suggests that smell can be 'designed in' cosmetically, as an artificial addition to the structure and/or space; naturally as would be the case when planting scented gardens, for example; or technically, which involves selecting building materials specifically on account of their smell - such as cedar wood. Examples of aroma-management technologies intended to re-odorise buildings have also begun to emerge. In 1990, a news article reported on Japanese-based Shiseido Co. Ltd's 'aromatic equipment', which their brochure suggested could deliver a “...lemon scent in the morning to wake workers up; a light floral scent to aid concentration at mid-morning; an odorfree [sic] lunch, and wood, lemon and floral scents in the afternoon” (Marx 1990, p. 1). 
Likewise, Japan's Shimuzu Corporation patented a fragrance system as part of a building's overall design. This delivers doses of different aromas into air conditioning ducts, which one assumes are controlled centrally by facilities managers according to pre-defined quantities and fragrances in a similar way to the Shiseido example above (Gaygen, \& Hedge 2009; Classen et al., 1994; Brumfield, \& Goldney, 2008). In UK organizations too, a newspaper article published in the year 2000 made reference to the travel company Thomas Cook's provision of a 'sensorama' corridor in its workplace, intended to impart a 'holiday-type' feeling to its call center workers through - among other stimuli - the smell of coconut oil (Williams, 2000). The article focused on how call centers were trying to shake off their negative image as 'dark satanic mills' and one assumes sensorially 'duping' staff into feeling in a holiday mood is an acceptable way to do this. More recently, a primary school in the UK experimented with pumping the scent of peppermint into class to aid children's concentration (Ross, 2010).

Such examples suggest that smell is an important resource in workplaces that see their employee behavior as the key to for better results, greater outputs or higher productivity. Brumfield et al. (2008, p. 254) mentions this in relation to workplaces where they claim:

"There are many objectives that can be met with a scent-based solution... our lives are becoming more hectic (not easier, as we once conceived), so anything we can do to create positive attitudes in the workplace should be done. The implementation of aromas in the office can help to accomplish this goal". 
In some senses this workplace impact is already underway: while practitioner and academic focus has been on smell in marketing, retail and branding, it is important to remember that retail, hospitality and spaces of service-provision are workplaces for those who are employed there. Others are experimenting with organizational dynamics in smell events themselves. For example, in a recent conference in the United States - 'Headspace: On Scent and Design' (www.headspace2010.com), a scented card was distributed to delegates infused with aromas purported to encapsulate different times of the day (for a review see Tischler, 2010).

And yet there is an irony in that while those designing our environments are increasingly using aroma as a resource, stakeholders immediately experiencing those environments have for the most part overlooked smell, with other senses such as vision being seen as culturally more important (Corbett, 2006). Public sanitation and hygiene measures have improved over the years to the extent that we have learned to forget smell to the extent that aroma management techniques can often pass unnoticed by those they are intended to shape. This may be part of the reason why despite olfactory interventions designing the ways we live, they are rarely interrogated in terms of the power or controlling aspects they present.

\section{I sniff therefore I am: subliminal olfactory control}

In thinking through the control power behind olfactory interventions, it is important to remember that much of this power is attributed to its subliminal influence. Sensory management, and smell in particular, assumes the ability for aromas to 'short-circuit' the conscious cognitive apparatus of the brain and evoke instantaneous and subliminal emotional responses. Marketers, architects, and increasingly organizations hope these will form associations or otherwise shape stakeholder behavior. Techniques reviewed above draw their legitimacy from scientific studies aimed at establishing the effect different fragrances and 
odors have on dimensions of human performance and behavior. Primarily psychological in nature, these studies typically involve experiments to isolate changes in participants' ability to carry out cognitive and behavioral tasks in response to the introduction of aromas in a controlled setting. For example, Zoladz and Raudenbush (2005) found that exposure to the scent of cinnamon and peppermint respectively raised attention, enhancing the operation of working memory and visual-motor response speed. This echoed earlier findings by Barker et al. (2003) establishing that the smell of peppermint improved clerical tasks including typing, memorization and alphabetization. Ho and Spence (2005) have shown that peppermint scent is a factor in improving the performance of difficult tasks. However, they also found that easier tasks were unaffected by the introduction of the smell, suggesting that certain odors can improve performance only where sustained concentration or complex mental processing is necessary. All of these processes position smell as cognitively determined with little or no discussion about individual preference or context being a potentially important component of the smell experience. For this reason they are particularly attractive to organizations since their (claims) of universalism transcend culture, group or individual and can therefore be applied to entire workforces.

Organizations are also likely to be persuaded by studies exploring the relationship between emotional behaviors and smell. Motomura, Sakurai, and Yotsuya (2001) found lavender reduced stress levels, and Lehrner, Eckersberger, Walla, Pötsch, and Deecke's (2000) earlier research showed how anxiety levels of female dental patients were reduced on exposure to the scent of orange oil. In a slightly different study, McBurney, Shoup, and Streeter (2006) identify the importance of partners' body scent left on clothing and smelled during periods of separation, while Liljenquist, Zhong, and Galinsky (2010) experimented with the 'scent of cleanliness' and found participants more willing to engage in virtuous behaviors - trust, 
reciprocity and charity - in a room smelling of a freshly sprayed citrus cleaning product. Relationships with other people are also mediated through smell. Zemke and Shoemaker (2006) showed how a pleasant ambient smell promotes social interaction among strangers while Moallem et al.'s (2007) research determined a positive effect of smell on social preferences when viewing photographs of other people, although they found that whilst subliminal odors shaped perceptions of others' favorably, conscious and/or stronger smells had disruptive effects - making impressions hard to form. Yet such studies neglect larger questions that face organizations surrounding the ethics of manipulating people when broader circuits of power, politics and hierarchies exist. For example, there is no discussion over what may be seen as the sovereignty of emotions - in other words, who has the 'right' to provoke or evoke these feelings in individuals and for what means.

These connections between smell and behavior are far from infallible. Phillips and Cupchik (2004) noted a link between inhaling scents while reading and the reader's engagement with the text and subsequent recall, but only when the smell was congruent with the reader's liking for, or identification with, the events of the story. Gaygen and Hedge (2008) did not find any effect of smell on participants' lexical decision performance. In fact, in the second experiment they conducted, a fragranced room was found to detract from decision-making ability. They assumed smell was a distractor as their research participants tried to work out what it was and where it was coming from - consciously or otherwise. Yet we do not see much evidence of this imperfect relationship considering different types, intensity, or contexts of smell as an inherent part of smell experiences for consumer, employee, patient, student or other groups. If different scents have different effects on different tasks, then how does one manage the diffusion of aromas to the myriad of tasks undertaken in complex organizations, for example? Furthermore, the studies above are set up to investigate cause 
and effect, rather than how smell is perceived by the smeller. How do they make meaning from the scent, based on their manifold, personal, biographical, psycho-social 'smell history'? In summary, the basis for a majority of aroma management techniques may both fail to acknowledge the broader questions surrounding power and control inherent in subliminal influence, and may also not take into account the historical, biographical cultural contexts that interplay with more cognitive processes surrounding smell.

\section{Between you and me: (Re)socializing smell as a political intervention}

Given that aroma management is only likely to increase in popularity as new technologies enable the facilitation and control of smell over time and space, it is likely organizations will increasingly explore smell practices within the workplace. It is therefore important to begin considering what the consequences may be for those who are living in these practices every day. This is especially so given that smells are not bounded by physical structure, floating on whatever current of air catches them and therefore permeating architectural and symbolic boundaries despite people's best efforts to contain them (see Riach \& Warren, 2015). By way of starting this debate, we outline three areas where olfactory practices are pertinent to larger debates surrounding organizational control.

First, there are very real health and safety considerations. Concern has already been raised about the 'chemical cocktails' that we associate with common aromas such as 'new car smell' (BBC, 2016), and these dangers may be exacerbated when any environment is deliberately altered. Gaygen and Hedge (2009) note that building fragrancing systems utilize complex mixtures of 'volatile organic compounds' (VOC's) to synthetically produce aroma. These can cause the irritation, allergic reaction, and other adverse health effects that have been linked to 
the so-called 'sick building syndrome'. As Wolkoff, Wilkins, Clausen, and Nielsen, (2006, p. 7) state, based on research into the effects of VOC's:

\author{
"Certain odors, in addition to odor annoyance, may result in psychological \\ effects and distraction from work. Some building materials continually \\ cause perceivable odors, because the odor thresholds of the emitted \\ compounds are low. Some oxidation products of alkenes (e.g. terpenes) \\ may contribute to eye and airway symptoms under certain conditions and \\ low relative humidity".
}

This indicates that the introduction of smell to workplaces may be hazardous to employee health, apart from the 'distraction from work' and 'annoyance' that is also recognized here. In support of this contention, albeit anecdotally, during the release of an ambient scent at the 'Headspace' conference discussed above, one delegate 'tweeted' that she had to leave the event early as the smells were making her feel nauseous (Twilley, 2010). Similarly, as Worwood (1995, p. 25) somewhat wryly observes, despite science starting to recognize what aromatherapists have been known for years (that smell has real effects on the body and mind), scientists are advocating artificial solutions "where even more man-made, synthetic, non biodegradable chemicals will be pumped into the atmosphere". This point is even more significant as we move towards buildings where people work with centralized air control systems through, for example, air conditioning or windows that cannot be easily opened, and subsequently do not allow individuals control of the immediate organizational smellscape.

Relatedly, such biological concerns also raise the question of whether spaces where people are required to be for a non-smell related purpose - such as the workplace - are an 
appropriate arena for aroma management in a social sense - natural or otherwise. Even without direct management olfactory intervention, workplaces are a political hotbed for smell politics. In a recent study we undertook to explore what might be at stake socially in the manipulation of office smellscapes (Riach \& Warren 2015), we found that smell may be one aspect of the communal experience of work, binding workers together. However, it could also differentiate individuals on account of ethnicity (e.g. what constitutes a 'smelly' lunch) or identity (e.g. what perfumes a woman of a particular age should wear to work). As such smells were experienced through organizationally dominant normative or exclusionary ideas of what work 'should' be and what was deemed a 'professionally' acceptable smell. While Tan (2013, p. 68), in her study of smokers in urban spaces advocates for such antagonistic olfactory politics to be retained rather than making way for "antiseptic urban environments", in workplace environments there is always unequal power relations that have the potential to reproduce difference and inequality in and through smell practices. If you are the person deemed to have 'the smelly lunch', then this not only carried symbolic but material effects on your everyday lived experience of work and perceptions of 'professionalism'. It is likely then, that explicit managerial intervention may only serve to further reproduce narrow idealizations of the 'model worker' in terms of what organizational smell practices are acceptable.

Finally, our study also leads to us to question the extent to which individuals can be fully duped by aroma management techniques. Some scientific research has already critiqued an acontextual approach to investigating smell. For example, Kirk-Smith and Booth (1987) argue that perception of fragrance is largely a product of the situation in which it is encountered, and the odor is only one ingredient in the perceiver's response. Elsewhere Dalton (1996) explains how much of the perception of smell is not a biologically determined 'top-down' 
process but 'top down' in that we make sense of smell according to conceptual schema and accumulated experience. It is this last point that Gaygen and Hedge $(2009$, p. 89) reinforce in their observation in regards to the workplace that is of specific concern to us here:

\footnotetext{
"[Our] result does not support our original hypothesis that the exposure to a pleasant but unidentifiable fragrance will facilitate performance on a lexical decision task and challenges simple assumptions that the introduction of fragrant air into a building will necessarily improve worker performance”.
}

Such accounts are valuable in reframing the politics of smell in organizational environments, not only through questioning their efficacy, but also allowing for a discussion of workers as individuals, who themselves are infused with various biographies, ideas, emotions and beliefs that allow them to creatively navigate the environments they find themselves in. This was just what Law (2001) found to be happening in her study of the 'sensory landscapes' created by Filipino women workers' weekly gatherings in a Hong Kong square. Law (2001, p. 279) eloquently shows how "a complex [sensory] articulation of nostalgia and desire" created situated resistances against dominant personal and social identities ascribed to the women on the basis of their economic and social status as domestic workers. In relation to workplaces, smell may be part of the ways employees actively connect with other workers, help transition between different tasks and duties, or simply relieve boredom during a long working day. It may be then, that aroma management is a means of creating an environment conducive for work, but only when employees are considered as more than neural receptors, and consulted about their own ideas and beliefs surrounding the organizational smellscape.

\section{Conclusion}


The prospects for designing smellscapes related to organizational workspaces are undoubtedly exciting and appeal to a broad range of architects, marketers and organizations. All of these professions and agencies are keen to realize added value from their stakeholders' capacity for sensory engagement. As we have suggested in this chapter, the use of smell in organizational contexts takes varied forms and is likely to increase given technological developments and more sophisticated neuro-biological understandings of how aroma 'works on' the brain and psychological processes. However, it is perhaps the intersection between biological and socio-cultural experiences of smell that provides greater opportunities for not only advancing the effective use of smell as a resource, but also allowing a discussion of the consequences and implications surrounding power and control as well as the possibilities presented through aroma management practices. Smell both enters the body as physical particles and has strong personal and cultural resonances. Reflecting on these dimensions and how they are entangled other marks an important step for smell designers. Rather than conceptualize smell as acting on bodies in space, we would urge designers to see bodies as actively doing things with smell.

\section{References}

Aromaco (n.d.). Senses (Harrods) from http://www.aromaco.co.uk/portfolio/senses/ last accessed April $6^{\text {th }} 2016$.

BBC (2016). Is new-car smell bad for your health?, Retrieved April $6^{\text {th }}, 2016$, from http://www.bbc.com/autos/story/20160315-is-new-car-smell-bad-for-your-health? 
Barker, S., Grayhem, P., Koon, J., Perkins, J., Whalen, A., \& Raudenbush, B. (2003).

Improved performance on clerical tasks associated with administration of peppermint odor. Perceptual and Motor Skills 97, 1007 - 1010.

Bielinis, S. (2007). NTT DoCoMo/ Sony Ericsson SO703i Aroma Phone, Unwired View, Retrieved September 11, 2015, from www.unwiredview.com/2007/01/23/ntt-docomosonyericsson-so703i/aroma-phone/

Brumfield, C. R., \& Gouldney, J. (2008). Whiff! The revolution of scent communication in the information age. New York: Quimby.

Classen, C., Howes, D., \& Synnott, A. (1994). Aroma: A cultural history of smell. London: Routledge.

Corbett, J. M. (2006). Scents of identity: Organisation Studies and the Cultural Conundrum of the Nose. Culture and Organization, 12(3), 221-232.

Derval, D. (2010). The right sensory mix. New York: Springer.

Diaconu, M. (2007). Olfactory design: strategies and applications, Working paper, Retrieved October 9, 2013, from http://www.sanart.org.tr/PDFler/33a.pdf .

Exhalia (n.d.). Genesis of the Prohect: The fragrant web of France Telecom, Retrieved April $6^{\text {th }} 2016$, from http://www.exhalia.com/us/societe/

Gaygen, D., \& Hedge, A, (2009). Effect of acute exposure to a complex fragrance on lexical decision performance. Chemical Senses, 34(1), 85-91.

Hamilos, P. (2004). Aaah! The sweet smell of socialism, The Guardian, retrieved September 18, 201, from http://www.theguardian.com/world/2008/jan/14/spain.paulhamilos,

Ho, C., \& Spence, C. (2005). Olfactory facilitation of dual-task performance. Neuroscience Letters, 389(1), 35-40. 
Hultén, B., Broweus, N., \& van Dijk, M. (2009). Sensory marketing. London: Palgrave.

Kirk-Smith, M.D., \& Booth, D.A. (1987). Chemoreception in human behaviour:

experimental analysis of the social effects of fragrances. Chemical Senses, 12(1), 159-166.

Krishna, A. (2010). Sensory marketing: research on the sensuality of products. London:

Routledge.

La Salle, D., \& Britton, T. (2003). Priceless: how to turn ordinary products into

extraordinary experiences. Cambridge MA: Harvard Business School Press.

Law, L. (2001). Home Cooking: Filipino women and geographies of the senses in Hong

Kong. Cultural Geographies, 8(3), 264-283.

Lehrner, J., Eckersberger, C., Walla, P., Pötsch, G., \& Deecke, L. (2000). Ambient odor of orange in a dental office reduces anxiety and improves mood in female patients. Physiology \& Behavior, 71(1), 83-86.

Liljenquist, K., Zhong, C., \& Galinsky S. (2010). The smell of virtue: Clean scents promote reciprocity and charity. Psychological Science, 21(3), 381-383.

Lindstrom, M. (2010). Brand sense: sensory secrets behind the stuff we buy. London: Kogan Page.

Malnar, J. M., \& Vodvarka, F. (2004). Sensory design. Minneapolis: University of Minnesota Press.

Marx, G. (1990). Bosses should Nix Job In-scent-ives, Newsday, retrieved September 11, 2015, from http://web.mit.edu/gtmarx/www/smell.html.

McBurney, D. H., Shoup, M. L., \& Streeter, S. A. (2006). Olfactory comfort: smelling a partner's clothing during periods of separation. Journal of Applied Social Psychology, 36(9), 2325-2335. 
Moallem, I., Paller, K., Gottfried, J. (2007) 'Subliminal smells can guide social preferences', Psychological Science, 18(12), 1044-1049.

Motomura, N., Sakurai, A., \& Yotsuya, Y. (2001). Reduction of mental stress with lavender odorant. Perceptual and Motor Skills, 93(3), 713-718.

Pallasmaa, J. (2005) The Eyes of the Skin: Architecture and the Senses, Chichester: John Wiley.

Phillips, K., \& Cupchik, G.C. (2004). Scented memories of literature. Memory, 12(3), 366375.

Pine, J., \& Gilmore, J. (1997). The experience economy. Boston: HBS Press.

Raudenbush, B. (2004). The effects of peppermint odor: A review of the literature and most recent findings. Aromachology, 12: 1-12

Renvoise, P., \& Morin, N. (2007). Neuromarketing: understanding the buy buttons in your customer's brain. Nashville: Thomas Nelson.

Riach, K., \& Warren, S. (2015). Smell Organisation: Bodies and corporeal porosity in office work. Human Relations, 68(5), 789-809.

Schmitt, B., \& Simonson, A. (1997). Marketing aesthetics: the strategic management of brands, identity and image. New York: Free Press.

Schmitt, B. (2000). Experiential marketing: how to get customers to sense, feel, think, act, relate to your company and brands. New York: Free Press.

Tan, Q. (2013). Smell in the City: Smoking and Olfactory Politics. Urban Studies, 50(1), 5571

Tischler, L. (2005). Smells like Brand Spirit, Fast Company, retrieved July 2, 2011, from http://www.fastcompany.com/magazine/97/brand-spirit.html 
Twilley, N. (2010). Ginger biscuits and deodorant guns, Edible Geography, retrieved

September 17, 2015, from http://www.ediblegeography.com/ginger-biscuits-and-deodorant-

guns/

Williams, E. (2000). 'Satanic mills' see the light. The Independent, 3 September, 2000.

Wolkoff, P., Wilkins, K. Clausen, P.A., \& Nielsen, G.D. (2006). Organic compounds in office environments - sensory irritation, odor, measurements and the role of reactive chemistry. Indoor Air, 16(1), 7-19.

Worwood, V. (1995). The fragrant mind. Reading: Bantam.

Zemke, D., \& Shoemaker, S. (2006). A sociable atmosphere: ambient scent's effect on social interaction. Cornell Hospitality Quarterly, 49(3), 317-329.

Zoladz, P., \& Raudenbush, B. (2005). Cognitive enhancement through stimulation of the chemical senses. North American Journal of Psychology, 7(1), 125-140.

i These technologies work using software that 'tells' a scent diffuser connected to the website visitor's computer what configuration of scent should be released. Thus, presently, extra equipment is needed for the process to work, both a diffuser and the concentrated aroma refills. However, given the speed at which technology develops we can probably expect scent diffusers to be standard features of computers and other technologies in the future. Sony Ericsson (now Sony Mobile Communications inc.) have already experimented with an aroma releasing phone to reduce stress (Bielinis, 2007) although at the time of writing there was no sign of such a product advertised on their website, suggesting it was not a popular addition to their portfolio. 